\title{
A rapid fractionation method for heavy metals in soil by continuous-flow sequential extraction assisted by focused microwaves
}

\author{
Tetsuya Nakazato • Mikio Akasaka • Hiroaki Tao
}

Published online: 17 January 2007

(C) Springer-Verlag 2007

Unfortunately, there were some typographical errors in this article. The corrections are given below.

In Fig. 3, the label on the $y$-axis should read "Relative extraction efficiency for heavy metals to BCR batchwise method (\%)".

In Table 2, the concentration units in "Amounts of heavy metals extracted from soil $\left(\mathrm{mg} \mathrm{g}^{-1}\right)$ " should be corrected from " $\mathrm{mg} \mathrm{g}^{-1}$ " to " $\mu \mathrm{g} \mathrm{g}^{-1}$ ".

The online version of the original article can be found at http://dx.doi. org/10.1007/s00216-006-0700-2.

T. Nakazato $(\bowtie) \cdot$ M. Akasaka $\cdot$ H. Tao

Research Institute for Environmental Management Technology,

National Institute of Advanced Industrial Science and Technology (AIST),

Onogawa 16-1,

Tsukuba 305-8569, Japan

e-mail: tet.nakazato@aist.go.jp

M. Akasaka

Japan Industrial Technology Association,

Higashi 1-1-1,

Tsukuba 305-0046, Japan

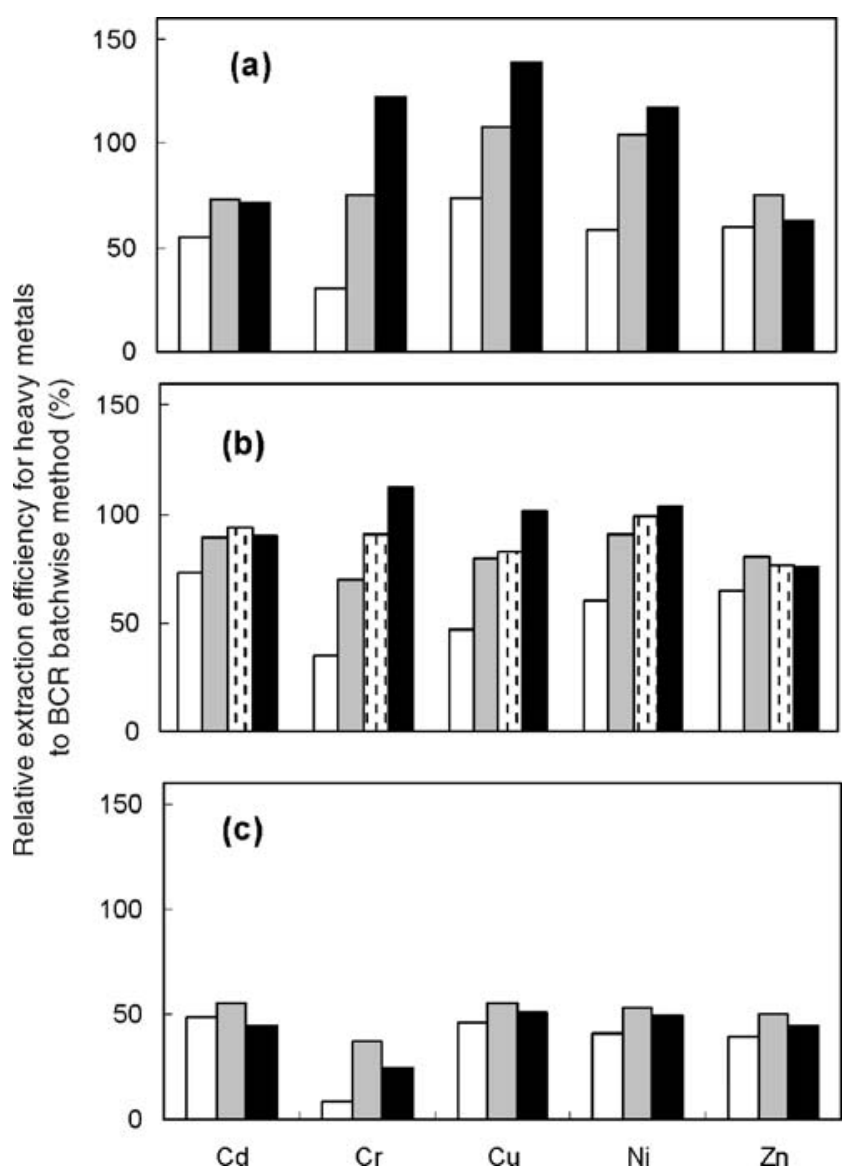

Fig. 3 Dependence of microwave power and the extractant flow rate on the extraction efficiency for heavy metals in step 1. Microwave power: $0 \mathrm{~W}$ (white bars), $10 \mathrm{~W}$ (shaded bars), $30 \mathrm{~W}$ (dashed bars), and $40 \mathrm{~W}$ (filled bars). Flow rates of the extractant in step 1:0 $1 \mathrm{~mL}$ $\min ^{-1}$ (a and $\mathbf{b}$ ) and $1.0 \mathrm{~mL} \mathrm{~min}{ }^{-1}(\mathbf{c})$. Length of soil column: $10 \mathrm{~mm}$ (a and c) and $5 \mathrm{~mm}(\mathbf{b})$ 